\title{
A NOVEL WIENER PROCESS MODEL WITH MEASUREMENT ERRORS FOR DEGRADATION ANALYSIS
}

\author{
ANALIZA DEGRADACJI Z ZASTOSOWANIEM NOWEGO MODELU \\ PROCESU WIENERA UWZGLĘDNIAJĄCEGO BŁĘDY POMIAROWE
}

\begin{abstract}
Degradation analysis can be used to assess reliability for complex systems and highly reliable products, because few or even no failures are expected in a reasonable life test span. In order to further our study on degradation analysis, an independent increment random process method with linear mean and standard deviation functions is presented to model practical degradation procedures. It is essentially a Wiener process method. Since measurement errors are often created by imperfect instruments, procedures and environments during degradation investigation, the measurement error is incorporated into the independent increment random process. Furthermore, statistical inferences of this model are discussed, and close forms of a product's median life and percentile of the failure time distribution (FTD) are also derived. The proposed method is illustrated and verified in a comprehensive simulation study and two practice applications for storage disks and Infrared light-emitting diodes. Meanwhile, the time-transformed Wiener process model with measurement error is considered as a reference method. Comparisons show that the proposed model can provide reasonable results, even in considerably small sample size circumstance.
\end{abstract}

Keywords: performance degradation, independent increment process, Wiener process model, linear mean function, linear standard deviation function, measurement error.

\begin{abstract}
Analizę degradacji można stosować do oceny niezawodności wysoce niezawodnych złożonych systemów i produktów, ponieważ $w$ ich przypadku istnieje bardzo niskie lub zerowe prawdopodobieństwo wystapienia uszkodzenia $w$ trakcie badania trwałości $w$ przyjętym okresie eksploatacji. $W$ artykule przedstawiono nowo opracowane podejście do modelowania procesu degradacji wykorzystujace metodę procesu o przyrostach niezależnych oraz pojęcia funkcji średniej liniowej i funkcji liniowego odchylenia standardowego. Zasadniczo jest to metoda oparta na procesie Wienera. Ponieważ badania degradacji często wiąża się z błędami pomiarowymi wynikającymi z niedoskonatości stosowanych narzędzi, procedur $i$ warunków badawczych, opisywany proces o przyrostach niezależnych uwzględnia błędy pomiaru. Ponadto, w pracy omówiono wnioski statystyczne, jakie można wyciagnąć na podstawie przedstawionego modelu oraz wyprowadzono wzory ogólne na średnia dlugość życia produktu oraz na percentyl rozktadu czasu do uszkodzenia. Proponowana metode zilustrowano i zweryfikowano na podstawie kompleksowego badania symulacyjnego oraz przykladów praktycznego zastosowania modelu w odniesieniu do dysków pamięci masowej oraz diod podczerwieni. $W$ artykule przedstawiono także model procesu Wienera z transformowanym czasem uwzględniający błąd pomiaru, który postuży za model referencyjny. Porównania pokazuja, że proponowany model może dawać poprawne wyniki, nawet przy bardzo małej liczebności próby.
\end{abstract}

Stowa kluczowe: obniżenie charakterystyk, proces o przyrostach niezależnych, model procesu Wienera, funkcja średniej liniowej, funkcja liniowego odchylenia standardowego, bład pomiaru.

\section{Introduction}

High reliable components and systems have been becoming more and more common in engineering as well as in our everyday life. Conventional failure data based methods encounter serious challenges because one cannot get enough failure data through general or accelerated life tests. Since most components and systems degrade over time, and can be considered to be failed when the deterioration accumulates beyond a predefined level (also called threshold level), degradation data can be taken as rich source life information in reliability assessment [9]. Once the failure has been detected, it is possible to access the FTD, infer reliability and accordingly predict the remaining useful life to take timely maintenance actions to avoid the catastrophic failures [12]. There has been a growing literature that is concerned with drawing reliability inferences from degradation data [8].

Lu and Meeker [6] concluded in their study that observed degradation on a specimen over time is a time series that can exhibit autocorrelation. Although they ignored the autocorrelation in their study, more and more deterioration models have taken this issue into consideration in the model construction procedure. Among these models, the Wiener process with positive drift is a favourable candidate due to its mathematical properties and physical interpretations [20]. The 
regular Wiener process $\{\eta(t), t \geq 0\}$ with drift $\beta$ and diffusion $\sigma$ can be expressed as the well-adopted form $[16,18]$ :

$$
\eta(t)=\beta \Lambda(t)+\sigma \mathbf{B}(\Lambda(t))
$$

where $\mathbf{B}(\cdot)$ denotes a standard Wiener process, and $\Lambda(t)$ is defined as a transformed time scale. From the basic definition of Wiener process, we know that $\{\eta(t), t \geq 0\}$ has $s$-independent and normally distributed increments; viz. $\Delta \eta(t)=\eta(t+\Delta t)-\eta(t)$ is $s$-independent of $\eta(t)$, and $\eta(t) \sim N\left(\beta \Lambda(t), \sigma^{2} \Lambda(t)\right)$.

There has been considerable interest on the part of the scientists and engineers in applying this process in degradation reliability analysis. Whitmore and Schenkelberg [18] presented a Wiener diffusion process with power-law time scale transformation to model self-regulating heating cables. Tseng and Peng [14] adopted an exponential transformed time scale to describe the deterioration path of a specific light emitting diode (LED) product. Park and Padgett [10] developed a generalized cumulative damage approach by describing initial damage with this process.

In practical engineering, it is inevitable that possible heterogeneities within a product population may exist due to geometry, material and other variations throughout the population. Specimens from the same population may share some commonalities and exhibit certain unit-specific properties as well. Therefore, Wiener process model with mixed effects is developed, where fixed effects capture the common characteristics while random effects describe the unit-to-unit differences. In real applications, drift $\beta$ for individual unit is usually assumed to be fixed but unknown, and follows a normal distribution $\beta \sim N\left(\mu, \kappa^{2}\right)$. This model was utilized by Crowder and Lawless [3] to analyze a wear procedure.

It should be noted from the Wiener process definition that the deterioration processes depicted by regular Wiener process and mixed effects models exhibit specific statistical properties. Certain relationship, also can be called limitation, exists between mean and variance because of the transformed time scale $\Lambda(t)$. Taking the linear transformed time scale situation (i.e., $\Lambda(t)$ is a linear function of test time) as an example, we should note that the regular Wiener process will illustrate both linear trend $\beta \Lambda(t)$ and variance $\sigma^{2} \Lambda(t)$. Although for the commonly used mixed effects model situation $\beta \sim N\left(\mu, \kappa^{2}\right)$, the Wiener process will exhibit a linear mean $\mu \Lambda(t)$ and a quadratic variance $\kappa^{2} \Lambda^{2}(t)+\sigma^{2} \Lambda(t)$, one should note that this quadratic variance is not a generalized one because of the only one transformed time scale $\Lambda(t)$.

To settle this problem, Tseng et al.[13] proposed a generalized Wiener process model for degradation analysis with two transformed time scales $\Lambda^{(1)}(t)$ and $\Lambda^{(2)}(t)$.

$$
\eta(t)=\beta \Lambda^{(1)}(t)+\sigma \mathbf{B}\left(\Lambda^{(2)}(t)\right)
$$

It can be concluded that Equation (2) is an improved degradation model comparing with Equation (1), because the previously mentioned correlation limitation between mean and variance of the regular Wiener process and mixed effects model can be broken through. It is worth noticing, however, that Tseng et al.[13] restricted their attention to the case $\Lambda^{(1)}(t)=\Lambda^{(2)}(t)$ in their study, because they concluded that it was rather difficult to obtain an explicit form of the lifetime

distribution when $\Lambda^{(1)}(t) \neq \Lambda^{(2)}(t)$. Therefore, they only proposed a general Wiener process model form with two transformed time scales without any essential studies or applications. From this viewpoint, the first objective of this paper is to study a commonly encountered case of the generalized Wiener process model expressed by Equation (2) via theoretical, simulation and empirical means.

In our previous work [17], we constructed a Wiener process model:

$$
\eta(t)=a+b t+\mathbf{B}\left(d t^{2}\right)
$$

It can be concluded as a special case of the generalized two-transformed time scale Wiener model expressed by Equation (2), where drift $\beta$ and diffusion $\sigma$ are both constants, $\Lambda^{(1)}(t)=a+b t$ and $\Lambda^{(2)}(t)=d t^{2}$. Measurement errors were not considered in the modeling procedure, i.e., deterioration observations were supposed to only reflect the inherent randomness of degradation itself.

To further depict the commonly encountered degradation situation of linear trend and generalized quadratic variance, we propose an improved model:

$$
\eta(t)=a+b t+\mathbf{B}\left(\left(d_{1}+d_{2} t\right)^{2}\right)
$$

where $a, b, d_{1}$ and $d_{2}$ are model parameters relating to linear mean and quadratic variance features, common for all units. Therefore, increment $\Delta \eta(t)=\eta(t+\Delta t)-\eta(t)$ is also $s$-independent of $\eta(t)$.

Comparing with the previously discussed regular Wiener process and mixed effects models, Equation (4) can be considered as a more generalized Wiener process model for the commonly encountered linear degradation path situation, because it can break through the correlation limit due to the only one transformed time scale $\Lambda(t)$. More important, degradation model of Equation (4) also can give a closed-form of FTD, and standard errors and confidence intervals for the parameter estimators can be directly understood and derived. Meanwhile, comparing with the generalized Wiener model form of Equation (2), Equation (4) is a special case by letting the two trans-

formed time scales $\Lambda^{(1)}(t)=a+b t$ and $\Lambda^{(2)}(t)=\left(d_{1}+d_{2} t\right)^{2}$, and the constant drift rate $\beta$ and diffusion coefficient $\sigma$ are incorporate into the transformed time scales.

On the other hand, it is inevitable that measurement errors may be introduced during the observation process in practical engineering. Therefore, Whitmore [18] described a Wiener diffusion model for measured degradation data that took both the inherent randomness of degradation itself and the measurement errors into account. He derived the sample log-likelihood function with the first differences of the inspections, the correlation among the observations on an item over time is consequently considered in his modeling procedure. Motivated by laser data [7], Peng and Tseng [11] proposed a generalized formulation of the linear degradation path in which the unit-to-unit variation, the time-dependent error structure and the measurement error were considered simultaneously. To utilize the first inspection of each unit, Ye et al. [20] improved the model in [18] and developed a time-transformed Wiener process model with measurement errors to analyze degradation of magnetic heads of hard disk drives. This 
improvement makes efficient remedy in real application, especially when the number of observations associated with each unit is small.

Thus, motivated by the practical need of including measurement errors in degradation analysis, the second objective of this study is to develop a generalized Wiener process model subject to measurement errors. Throughout this paper, the deterioration measurement at time $t$ is denoted by $Y(t)$, and the corresponding true level of degradation at this time is denoted by $\eta(t)$. Then the statistical model relating degradation measurement $Y(t)$ to the true deterioration level $\eta(t)$ is assumed to be the following:

$$
Y(t)=\eta(t)+e(t)
$$

where $e(t)$ denotes the measurement errors that are assumed to be i.i.d. realization of $e(t) \sim N\left(0, \sigma_{e}^{2}\right)$.

We call this proposed Wiener process model with measurement errors expressed by Equation (4) the simple model. And we will illustrate it in Section 2. In this study, consequently, we improve the Wiener process model of Equation (4) via taking measurement errors into consideration, and further investigate a more generalized model.

The remainder of the paper is organized as follows. Section 2 introduces the simple Wiener process degradation model with linear trend and quadratic variance. Section 3 takes measurement errors into the simple model and gives the model description, MLE for unknown parameter and initial guesses for optimization algorithm. In Section 4 , the efficiency and reasonability of our methodology is validated comparing with the Wiener processes with measurement errors in [20] via a Monte Carlo simulation study. In Section 5, the proposed approach is illustrated by two applications including storage disks degradation analysis and Infrared light-emitting diodes (IRLEDs) degradation analysis, and comparative results are given. A summary and conclusion is given in Section 6.

\section{The simple Wiener processes degradation model}

Experimental results provide an observed sequence of degradation readings $z$ over test time $t$ for each sample unit. The observed degradation $z$ is a unit's actual degradation. "Time" $t$ could be real test time or some other measure like cycles in fatigue tests. We make the following general assumptions about the manner in which the test is conducted.

1) Sample units are randomly selected from a population or production process. We use this assumption for ensuring the independence of measurements for individual item, and ensuring the population reliability inference reasonability based on the tested sample.

2) The degradation is a non-return process (eg, when in discussion with unmaintainable systems with stable intensity of use); viz. a unit can be declared as having failed when its degradation reaches a critical threshold [4].

3) The first test time is prespecified, the same across all the test units, but not necessarily to be zero. This can be realized via proper transforming when the first test times are not all the same in practical degradation test. Then test times can be different for individual item, and may or may not be equally spaced in time.

Based on our previous study and analysis, the mean and standard deviation of some degradation process can both be considered as linear function of test time, or transformed test time when this relationship cannot be found directly. Consequently, in order to construct a generalized method, we define the following two transformation functions. One is an appropriate monotone increasing time transfor- mation $x=f_{1}(t)$, where $t$ denotes the test time, and $x$ corresponds to the transformed test time. The other one is performance parameter transformation $y=f_{2}(z)$, where $z$ denotes the measurement in the degradation test, and $y$ is the transformed degradation value. These two transformation functions can be obtained by engineering experience, mechanistic knowledge (see the wearing theory in [15]) or data plotting (see the complex logarithmic transformation in [21]). Particularly, let $x=t$ and $y=z$ when linear mean relationship between degradation measurement $z$ and test time $t$ can be established directly.

Then the Wiener process proposed in this paper with linear mean $\mu(x)=a+b x$ and linear standard deviation $\sigma(x)=d_{1}+d_{2} x$ can be defined through the following assumptions.

1) Suppose $m$ items are put into test. The performance of unit $i$ is measured (or inspected) at $n_{i}$ prespecified times $t_{1}<t_{i 2}<\cdots<t_{i n_{i}}$ with corresponding measurements $z_{i 1}$, $z_{i 2}, \cdots, z_{i n_{i}}, i=1,2, \cdots, m$.

2) If necessary, construct the time transformation $x=f_{1}(t)$ and/ or performance parameter transformation $y=f_{2}(z)$. Then the transformed performance increments $y_{i 2}-y_{i 1}, y_{i 3}-y_{i 2}, \ldots$, $y_{i n}-y_{i(n-1)}$ are inter-independent for all items $i=1,2, \cdots, m$.

3) The increment $y_{i j}-y_{i(j-1)}$ follows a normal distribution:

$$
\begin{gathered}
y_{i j}-y_{i(j-1)} \sim N\left(b\left(x_{i j}-x_{i(j-1)}\right), 2 d_{1} d_{2}\left(x_{i j}-x_{i(j-1)}\right)+d_{2}^{2}\left(x_{i j}^{2}-x_{i(j-1)}^{2}\right)\right) \\
i=1,2, \cdots, m \quad j=2,3, \cdots, n
\end{gathered}
$$

where $b=\partial \mu(x) / \partial x$ is the constant mean degradation rate; and $d_{2}=\partial \sigma(x) / \partial x$ depicts the increasing rate of standard deviation, also a constant.

4) The first transformed measurement $y_{i 1}$ is independent of the increments $y_{i 2}-y_{i 1}, y_{i 3}-y_{i 2}, \cdots, y_{i n}-y_{i(n-1)}$ and follows a normal distribution:

$$
y_{i 1} \sim N\left(\mu_{1}, \sigma_{1}^{2}\right) \quad i=1,2, \cdots, m
$$

where $\mu_{1}$ and $\sigma_{1}^{2}$ are the mean and variance of the transformed degradation measurements at the first transformed test time $x_{1}$.

Based on the properties of Wiener processes and the model assumptions mentioned above, $y_{i j}$ also follows a normal distribution:

$$
\begin{aligned}
& y_{i j}=a+b x_{i j}+\varepsilon\left(x_{i j}\right) \\
& \varepsilon\left(x_{i j}\right) \sim N\left(0,\left(d_{1}+d_{2} x_{i j}\right)^{2}\right) \\
& \operatorname{Cov}\left(\varepsilon\left(x_{i j}\right), \varepsilon\left(x_{i k}\right)\right)=\left(d_{1}+d_{2} x_{i j}\right)^{2} \quad x_{i j} \leq x_{i k}
\end{aligned}
$$

where $a, b, d_{1}$ and $d_{2}$ are unknown parameters, common for all items. We can further concluded that variance of $y_{i j}$ can be depicted by $\operatorname{Var}\left(y_{i j}\right)=\sigma^{2}\left(x_{i j}\right)=\left(d_{1}+d_{2} x_{i j}\right)^{2}$.

From the Wiener process definition, its standard deviation can be concluded to be an increasing function of time, which yields that 
$d_{1} \geq 0$ and $d_{2}>0$. Particularly, when $d_{1}=0$, standard deviation will be $\sigma(x)=d_{2} x$, then the degradation model will become the one we have established in [17]. Based on the statistical models expressed by Equation (2) and Equation (8), our proposed methodology is essentially the Wiener process model $y_{t}=a+b x+B\left(\left(d_{1}+d_{2} x\right)^{2}\right)$ from a different viewpoint, where the statistical properties can be intuitively drawn.

\section{The improved model with measurement errors}

\subsection{Model Assumption}

Let $x=t, y=z$, and suppose $\eta(t)$ is a unit's actual degradation. Then, based on the statistical models expressed by Equation (4) and Equation (5), the statistical model relating degradation measurement $Y(t)$ to the true deterioration level $\eta(t)$ is assumed to be the following:

$$
Y(t)=a+b t+B\left(\left(d_{1}+d_{2} t\right)^{2}\right)+e(t)
$$

where $e(t)$ denotes the measurement errors that are assumed to be i.i.d. realization of $e(t) \sim N\left(0, \sigma_{e}^{2}\right)$. The $e(t)$ is assumed to be mutually independent of each other and of the $\eta(t)$.

Suppose the deterioration is inspected at ordered times $\boldsymbol{t}=\left\{t_{1}, t_{2}, \ldots, t_{n}\right\}, \quad$ with observed degradations $\left\{Y_{1}=y_{1}, Y_{2}=y_{2}, \ldots, Y_{n}=y_{n}\right\}$, where $Y_{i}=\eta_{i}+e_{i}$. Define the increment $\Delta Y_{1}=Y_{1}, \quad \Delta y_{1}=y_{1}, \lambda_{1}=a+b t_{1} \quad$ and $\quad \Delta Y_{i}=Y_{i}-Y_{i-1}, \Delta y_{i}=y_{i}-y_{i-1}$, $\lambda_{i}=b\left(t_{i}-t_{i-1}\right)$ for $i=2,3, \ldots, n$. Then $\Delta \boldsymbol{Y}=\left\{\Delta Y_{1}, \ldots, \Delta Y_{n}\right\}$ follows a multivariate normal distribution $N(b \lambda, \Sigma)$ with a joint probability density function (PDF):

$$
f_{\Delta \boldsymbol{Y}}(\Delta \boldsymbol{y})=(2 \pi)^{-\frac{n}{2}} \mid \Sigma^{-\frac{1}{2}} \exp \left[-\frac{1}{2}(\Delta \boldsymbol{y}-\lambda)^{\prime} \Sigma^{-1}(\Delta \boldsymbol{y}-\lambda)\right]
$$

where $\Delta \boldsymbol{y}=\left(\Delta y_{1}, \Delta y_{2}, \ldots, \Delta y_{n}\right)^{\prime}$ is a realization of $\Delta \boldsymbol{Y}$, $\lambda=\left(\lambda_{1}, \lambda_{2}, \ldots, \lambda_{n}\right)^{\prime}$, and the variance matrix $\Sigma$ is a positive definite matrix with the $(i, j)$ th element given by:

$\sum_{i, j}=\operatorname{cov}\left(\Delta Y_{i}, \Delta Y_{j} \mid b\right)=\left\{\begin{array}{cc}\left(d_{1}+d_{2} t_{i}\right)^{2}+\sigma_{e}^{2} & i=j=1 \\ 2 d_{2} \Delta t_{i}\left(d_{1}+d_{2} \bar{t}_{i}\right)^{2}+2 \sigma_{e}^{2} & i=j>1 \\ -\sigma_{e}^{2} & i=j+1 \text { or } i=j-1 \\ 0 & \text { otherwise }\end{array}\right.$

where $\Delta t_{i}=t_{i}-t_{i-1}$ and $\bar{t}_{i}=\left(t_{i}+t_{i-1}\right) / 2, i=2,3, \ldots, n$.

\subsection{Failure Time Distribution}

The distribution function of the degradation characteristic $y$ at time $t$ can be given by:

$$
F_{Y}(y \mid t)=\Phi\left(\frac{y-a-b t}{\sigma_{0}(t)}\right)
$$

where $\sigma_{0}(t)=\sqrt{\left(d_{1}+d_{2} t\right)^{2}+\sigma_{e}^{2}}$, and $\Phi(\cdot)$ is the distribution function of the standard normal distribution.

The failure state of the product can be defined by the event $y>D_{\mathrm{f}}$ or $y<D_{\mathrm{f}}$, where $D_{\mathrm{f}}$ is a particular "critical" level for product performance. According to this definition, product reliability is the probability of the product being in normal state in the time interval $[0, t]$. Consequently, FDT can be defined as:

$$
F_{T}\left(t \mid D_{\mathrm{f}}\right)=P\left\{T \leq t \mid D_{\mathrm{f}}\right\}=1-\Phi\left(\frac{D_{\mathrm{f}}-\mu(t)}{\sigma_{0}(t)}\right)
$$

if $b>0$, or as:

$$
F_{T}\left(t \mid D_{\mathrm{f}}\right)=P\left\{T \leq t \mid D_{\mathrm{f}}\right\}=\Phi\left(\frac{D_{\mathrm{f}}-\mu(t)}{\sigma_{0}(t)}\right)
$$

when $b<0$.

As important characteristics, the FTD percentiles are elemental in reliability and safety analysis. Let $t_{p}$ be the $100 p$ th percentile of the FTD, i.e. an average of $100(1-p) \%$ of the population of the product will not fail before $t_{p}$. Then solving:

$$
F_{T}\left(t \mid D_{\mathrm{f}}\right)=p
$$

with respect to $t$ yields the percentile $t_{p}$. Taking $p=0.50$ for example, the median life associated with the FTD in practical applications, can be derived.

\subsection{Parameter Estimation}

Let $\Theta$ be the vector of all unknown parameters; viz. $\Theta=\left(a, b, d_{1}, d_{2}, \sigma_{e}^{2}\right)$. Suppose that the degradation processes of $m$ units have common inspection times given by $t$. The degradation measurements for unit $k$ are given by $\boldsymbol{y}_{k}=\left\{y_{k 1}, y_{k 2}, \ldots, y_{k n}\right\}$. Again, we work on the increments $\Delta \boldsymbol{y}_{k}$. Based on Equation (10) and Equation (11), the log likelihood function can be written as:

$$
l(Y \mid \Theta)=C-\frac{m}{2} \ln |\Sigma|-\frac{1}{2} \sum_{k=1}^{m}\left(\Delta \boldsymbol{y}_{k}-\lambda\right)^{\prime} \Sigma^{-1}\left(\Delta \boldsymbol{y}_{k}-\lambda\right)
$$

where $C$ denotes a generic constant that may change from line to line throughout this paper.

Subsequently, the maximum likelihood estimation (MLE) of $\Theta=\left(a, b, d_{1}, d_{2}, \sigma_{e}^{2}\right)$ can be obtained by maximizing the log likelihood function. However, it is very tough for direct constrained optimization of the log-likelihood function Equation (16). The genetic algorithm (GA) provides a possible way for resolving this problem. GA can be understood as an "intelligent" probabilistic search algorithm which can be applied to a variety of combinatorial optimization problems. GA is composed of evaluation-step, selection-step and reproduction- step. This evaluation-selection-reproduction cycle is repeated until a satisfactory solution is found. GA is considerably simple and converges reliably. A more comprehensive overview of GAs can be found in $[1,5]$. 


\subsection{Initial Guesses}

When GA is applied to numerically maximize the log likelihood function, we start with an initial guess that is reasonably close to the MLE of the unknown parameters $\Theta=\left(a, b, d_{1}, d_{2}, \sigma_{e}^{2}\right)$. This start is especially important if the data size is large (i.e., a large prespecified inspection times $n$ for each unit), because under this scenario the likelihood function becomes much more complex with possibly many local optima, and each step takes a long time to evaluate. A bad starting point would result in a very slow convergence, as well as a local optimum far away from the true MLE. This subsection develops a two-step procedure to make an educated guess for the initial intervals of the unknown parameters. The basic idea is as follows. For $m$ degradation units, the rough estimates for $a$ and $b$ can be obtained by fitting the degradation data based on the standard least squares approach. Then, by treating the rough estimators as the true values, the problem reduces to the estimation of the unknown parameters $d_{1}, d_{2}$ and $\sigma_{e}^{2}$. The detailed procedure is as follows:

Step 1 . Get rough estimates of $a$ and $b$ by minimizing the mean squared error (MSE) MSE $=\sum_{i=1}^{n}\left(\bar{y}_{i}-a-b t_{i}\right)^{2}$, where $\bar{y}_{i}=\frac{1}{m} \sum_{j=1}^{m} y_{i j}$.

Step 2. By fixing $a$ and $b$ at the rough estimates obtained from

step 1 , get rough estimates of $d_{1}, d_{2}$ and $\sigma_{e}^{2}$ by maximizing the log

likelihood function $l\left(d_{1}, d_{2}, \sigma_{e}^{2}\right)$.

After obtaining the rough estimates from the above two-step procedure, legitimate initial guesses of $d_{1}, d_{2}$ and $\sigma_{e}^{2}$ are obtained. In conjunction with the initial guesses of $a$ and $b$ from Step 1, the starting intervals of the unknown parameters for maximizing the log likelihood function Equation (16) based on GA are determined.

\section{Simulation Experiments}

To demonstrate the reasonability of the proposed independent increment process degradation approach, a comprehensive Monte Carlo simulation study is conducted. For clear, let $\mathrm{M}_{0}$ denote the proposed model. The Wiener process with measurement errors in [20] is considered as a reference method $\mathrm{M}_{1}$ for comparison. To settle the linear degradation path problem, we assume the transformed time scale to be $\Lambda(t)=a+b t$, and let $\beta \sim N\left(\mu, \kappa^{2}\right)$ be a normally distributed random effect. As discussed in Section 1, the degradation process then follows a normal distribution with a linear mean and quadratic

$$
\text { variance } \quad Y(t) \sim N(\mu \Lambda(t),
$$$$
\left.\kappa^{2} \Lambda^{2}(t)+\sigma^{2} \Lambda(t)+\sigma_{e}^{2}\right) \text {. Without loss of }
$$

generality in simulation, degradation data are first simulated based on the proposed model, and then the model presented in [20] and our model are adopted to fit the simulated degradation. Based on simulation studies, we found that if the degradation model of Equation (10) is utilized to generate the deg- radation data, not all simulated deterioration processes can be properly depicted by [20] because the limitation between mean and variance functions. To illustrate this important issue, we give two examples here.

\subsection{Example 1}

Without loss of generality, we simulate the degradation data of $m$ products with parameters $a=3.5, b=1.8, d_{1}=0.5, d_{2}=0.18$ and $\sigma_{e}^{2}$ $=1$. Each product is measured $n$ times with the measured frequency of $\Delta t=1$. Given that the degradation threshold is $D_{f}=24$. The value of $(n, m)$ is chosen to be $(10,5),(10,10),(10,20)$ and $(15,5)$ sequentially. For each combination of $(n, m), \mathrm{MSE}$ and the mean relative error (MRE) for model parameters $\left(a, b, d_{1}, d_{2}, \sigma_{e}^{2}\right)$ of the proposed model are estimated based on 5000 Monte Carlo replications. Furthermore, the MSEs and the MREs of the median life $t_{0.5}$ and the 5 th

percentile of FTD $t_{0.05}$ are obtained to compare the estimated accuracy of the proposed model with the reference model. The results obtained are listed in Table 1 and Table 2 respectively.

Table 1 shows that the MSE and MRE of parameters based on the proposed model are considerably small, and when the number of test unit $m$ increases, the MSE and MRE of parameters become smaller. When the number of measured time points $n$ increases, the MSE and MRE of parameters also become smaller but not significantly. One should further note that the MRE of $d_{1}, d_{2}$ and $\sigma_{e}^{2}$ are relatively big, this is because their true values are considerably small, then any small estimation bias will lead to a rather large relative error.

From Table 1 and Table 2, it can be observed that the MSE and MRE of the median life and the 5th percentile of FTD based on our model are significantly smaller than the estimated results obtained by the reference model. In addition, the MRE of the median life are less than 0.05 when the sample size is greater than 10 for both methods. However, for the proposed model, MRE is less than 0.05 even for a sample size of 5. For all situations, MRE of the 5th percentile of FTD based on our model are only nearly half of that based on the reference model. Therefore, for the purpose of obtaining more accurate results, proper degradation models should be considered. In other words, if the degradation model is mis-specified, it may lead to unreliable results.

Table 1. MSE and MRE of the estimates from $M_{0}$

\begin{tabular}{cccccccccc}
\hline \hline \multirow{2}{*}{$(n, m)$} & \multicolumn{2}{c}{$(10,5)$} & \multicolumn{2}{c}{$(10,10)$} & \multicolumn{2}{c}{$(10,20)$} & \multicolumn{2}{c}{$(15,5)$} \\
\cline { 2 - 9 }$a$ & MSE & MRE & MSE & MRE & MSE & MRE & MSE & MRE \\
\cline { 2 - 9 } & 0.26380 & 0.11849 & 0.12397 & 0.08077 & 0.06180 & 0.05696 & 0.23061 & 0.10861 \\
$b$ & 0.01487 & 0.05400 & 0.00726 & 0.03827 & 0.00375 & 0.02691 & 0.01058 & 0.04576 \\
$d_{1}$ & 0.11069 & 0.58424 & 0.06927 & 0.43850 & 0.04552 & 0.34930 & 0.10608 & 0.56923 \\
$d_{2}$ & 0.00694 & 0.37162 & 0.00318 & 0.24760 & 0.00166 & 0.17936 & 0.00309 & 0.24288 \\
$\sigma_{e}^{2}$ & 0.11534 & 0.27040 & 0.05950 & 0.19331 & 0.02812 & 0.13462 & 0.08533 & 0.23154 \\
$t_{0.5}$ & 0.45964 & 0.04661 & 0.21803 & 0.03254 & 0.11324 & 0.02354 & 0.33809 & 0.04058 \\
$t_{0.05}$ & 0.49521 & 0.05963 & 0.20037 & 0.03826 & 0.10238 & 0.02765 & 0.29164 & 0.04591 \\
\hline \hline
\end{tabular}


Table 2. MSE and MRE of the median life and the 5th percentile of FTD from $M_{1}$

\begin{tabular}{ccccccccc}
\hline \hline \multirow{2}{*}{$(n, m)$} & \multicolumn{2}{c}{$(10,5)$} & \multicolumn{2}{c}{$(10,10)$} & \multicolumn{2}{c}{$(10,20)$} & \multicolumn{2}{c}{$(15,5)$} \\
\cline { 2 - 8 } & MSE & MRE & MSE & MRE & MSE & MRE & MSE & MRE \\
\cline { 2 - 8 }$t_{0.5}$ & 1.28479 & 0.07428 & 0.55868 & 0.04963 & 0.29128 & 0.03565 & 1.23724 & 0.07304 \\
$t_{0.05}$ & 1.35546 & 0.09738 & 0.65970 & 0.06972 & 0.38257 & 0.05354 & 1.01684 & 0.08234 \\
\hline \hline
\end{tabular}

To further compare the difference, we calculate the log-likelihood function (Log-LF) for each simulated data set. Then the average LogLF and the corresponding Akaike information criterion (AIC) value are obtained, and the results are displayed in Table 3.

Table 3. Comparison between $M_{0}$ and $M_{1}$

\begin{tabular}{ccccc}
\hline \hline \multirow{2}{*}{$(n, m)$} & \multicolumn{3}{c}{$\mathrm{M}_{0}$} & \multicolumn{2}{c}{$\mathrm{M}_{1}$} \\
\cline { 2 - 5 }$(10,5)$ & Log-LF & AIC & Log-LF & AIC \\
\cline { 2 - 5 }$(15,5)$ & -84.74 & 179.49 & -87.37 & 186.74 \\
$(10,10)$ & -131.85 & 273.70 & -136.49 & 284.98 \\
$(10,20)$ & -172.31 & 354.61 & -176.53 & 365.06 \\
\hline \hline
\end{tabular}

\subsection{Example 2}

To test the effect of measurement error, let $\sigma_{e}^{2}=2$ and keep other parameters unchanged, we simulate the degradation data.

For each combination of $(n, m)$, the MSE and the MRE for parameters $\left(a, b, d_{1}, d_{2}, \sigma_{e}^{2}\right)$

of the proposed model are again estimated based on 5000 Monte Carlo replications. Furthermore, the MSE and the MRE of the median life $t_{0.5}$ and the 5 th percentile of FTD $t_{0.05}$ are obtained to compare the estimated accuracy of the two models. The results are displayed in Table 4 and Table 5.

From Table 4 and Table 5, it can be concluded that MSE and MRE of parameters are small. MSE and MRE of median life and the 5th percentile of FTD based on our model are smaller than the reference model. Moreover, the MSE and MRE is a little larger than that in Section 4.1 because the measurement error increases, but this change is not very significant. It shows that our model and the reference model still can provide precise estimates even when the measurement error becomes larger. However, the estimated results are more accuracy based on our model.
Table 4. MSE and MRE of the estimates from $M_{0}$ with $\sigma_{e}^{2}=2$

\begin{tabular}{ccccccccc}
\hline \hline \multirow{2}{*}{$(n, m)$} & \multicolumn{2}{c}{$(10,5)$} & \multicolumn{2}{c}{$(10,10)$} & \multicolumn{2}{c}{$(10,20)$} & \multicolumn{2}{c}{$(15,5)$} \\
\cline { 2 - 8 }$a$ & MSE & MRE & MSE & MRE & MSE & MRE & MSE & MRE \\
\cline { 2 - 8 } & 0.35732 & 0.13585 & 0.18803 & 0.09929 & 0.09070 & 0.06848 & 0.30942 & 0.12606 \\
$b$ & 0.01693 & 0.05755 & 0.00896 & 0.04196 & 0.00445 & 0.02960 & 0.01112 & 0.04683 \\
$d_{1}$ & 0.11282 & 0.60780 & 0.08987 & 0.52449 & 0.05958 & 0.40829 & 0.12081 & 0.61106 \\
$d_{2}$ & 0.00887 & 0.43454 & 0.00492 & 0.31110 & 0.00232 & 0.21554 & 0.00442 & 0.29287 \\
$\sigma_{e}^{2}$ & 0.28193 & 0.22025 & 0.16406 & 0.16294 & 0.08109 & 0.11429 & 0.22876 & 0.19370 \\
$t_{0.5}$ & 0.46760 & 0.04703 & 0.24449 & 0.03450 & 0.12272 & 0.02463 & 0.34283 & 0.04061 \\
$t_{0.05}$ & 0.49531 & 0.06087 & 0.23498 & 0.04215 & 0.11174 & 0.02923 & 0.32773 & 0.04890 \\
\hline \hline
\end{tabular}

Table 5. MSE and MRE of the median life and the 5th percentile of FTD from $M_{1}$ with $\sigma_{e}^{2}=2$

\begin{tabular}{ccccccccc}
\hline \hline \multirow{2}{*}{$(n, m)$} & \multicolumn{2}{c}{$(10,5)$} & \multicolumn{2}{c}{$(10,10)$} & \multicolumn{2}{c}{$(10,20)$} & \multicolumn{2}{c}{$(15,5)$} \\
\cline { 2 - 8 } & MSE & MRE & MSE & MRE & MSE & MRE & MSE & MRE \\
\cline { 2 - 8 }$t_{0.5}$ & 1.03008 & 0.06834 & 0.56829 & 0.04996 & 0.30952 & 0.03654 & 1.46605 & 0.07764 \\
$t_{0.05}$ & 1.09847 & 0.09086 & 0.66783 & 0.07094 & 0.39708 & 0.05587 & 1.13559 & 0.08756 \\
\hline \hline
\end{tabular}

Table 6. Comparisons of two fitted degradation models

\begin{tabular}{ccccccccc}
\hline \hline Model & \multicolumn{7}{c}{ Parameters } \\
\hline $\mathrm{M}_{1}$ & $a$ & $b$ & $\mu$ & $\kappa^{2}$ & $\sigma^{2}$ & $\sigma_{e}^{2}$ & Log-LF & AIC \\
\cline { 2 - 9 } & 0.3187 & 0.1320 & 1.9340 & 0.0060 & 0.2092 & 0.0054 & 30.30 & -48.60 \\
& $a$ & $b$ & $d_{1}$ & $d_{2}$ & -- & $\sigma_{e}^{2}$ & Log-LF & AIC \\
$\mathrm{M}_{0}$ & & & & & & & & \\
& 0.5573 & 0.2187 & 0.2322 & 0.0604 & -- & 0.0025 & 32.29 & -54.57 \\
$\mathrm{M}_{2}$ & 0.5647 & 0.2135 & 0.2334 & 0.0708 & -- & -- & 30.23 & -52.46 \\
\hline \hline
\end{tabular}

\section{Illustrative Example}

\subsection{Storage disks degradation modeling}

The block error rates of magnetooptic data storage disks increases over time, and this increase leads to a soft failure when the block error rate reaches a critical value. Many tests have been carried out to collect degradation data to investigate the degradation behavior of magneto-optic data storage disks. A dataset was presented in [7], where 16 units were tested for 2000 hours at $80{ }^{\circ} \mathrm{C}$ and $85 \%$ relative humidity. The failure threshold level of block error rate is $D_{f}=5$. The degradation paths are depicted in Fig. 1.

We firstly begin with a preliminary statistical analysis by calculating the mean $\mu(t)$ and standard deviation $\sigma(t)$ at each measured time point, and the results are shown in Fig. 2. From Fig. 2, we can observe that the mean degradation path and the standard deviation are
For each combination of $(n, m)$ shown in Table 3 , it is clear that the proposed model always outperforms the reference model both in terms of the LogLF and AIC. Therefore, in some cases, it is necessary to use the proposed model to capture the degradation over time for obtaining more accurate results. 

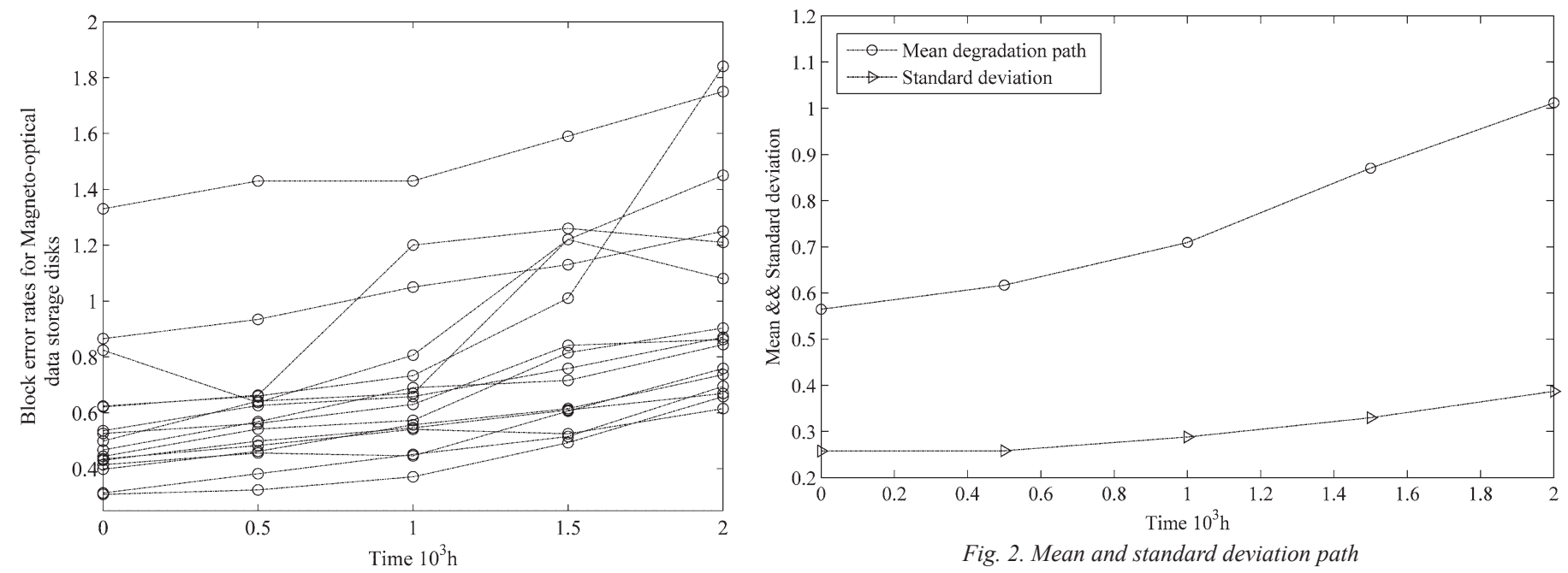

Fig. 2. Mean and standard deviation path

Fig. 1. Degradation paths of 16 magneto-optic data storage disks

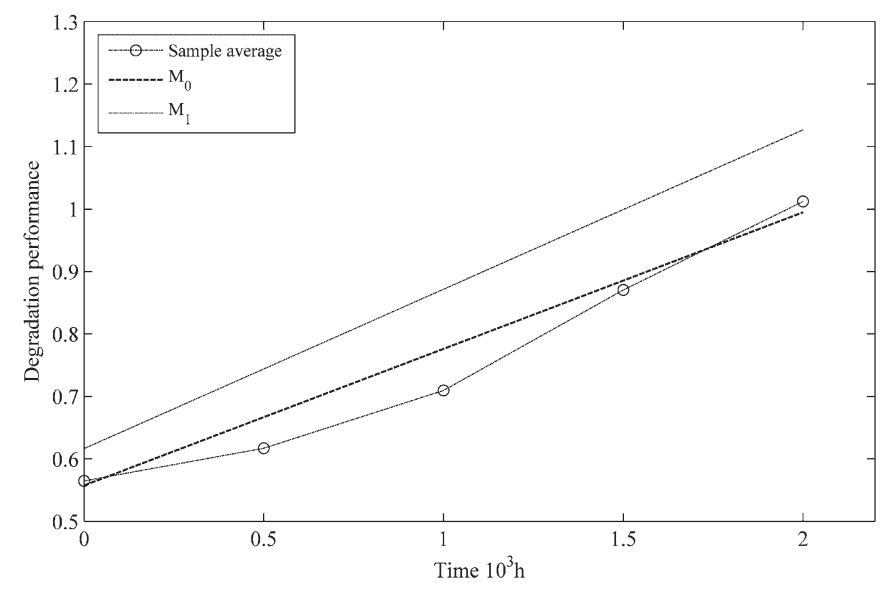

Fig. 3. Estimated mean paths based on $M_{0}$ and $M_{1}$

Table 7. The estimated median life and 10th percentile of FTD

\begin{tabular}{ccc}
\hline \hline \multirow{2}{*}{ Failure time/10 $\mathrm{h} h$} & \multicolumn{2}{c}{ Model } \\
\cline { 2 - 3 } & $\mathrm{M}_{0}$ & $\mathrm{M}_{1}$ \\
\hline$\hat{t}_{0.50}$ & 20.31 & 17.17 \\
$\hat{t}_{0.10}$ & 14.00 & 13.70 \\
\hline \hline
\end{tabular}

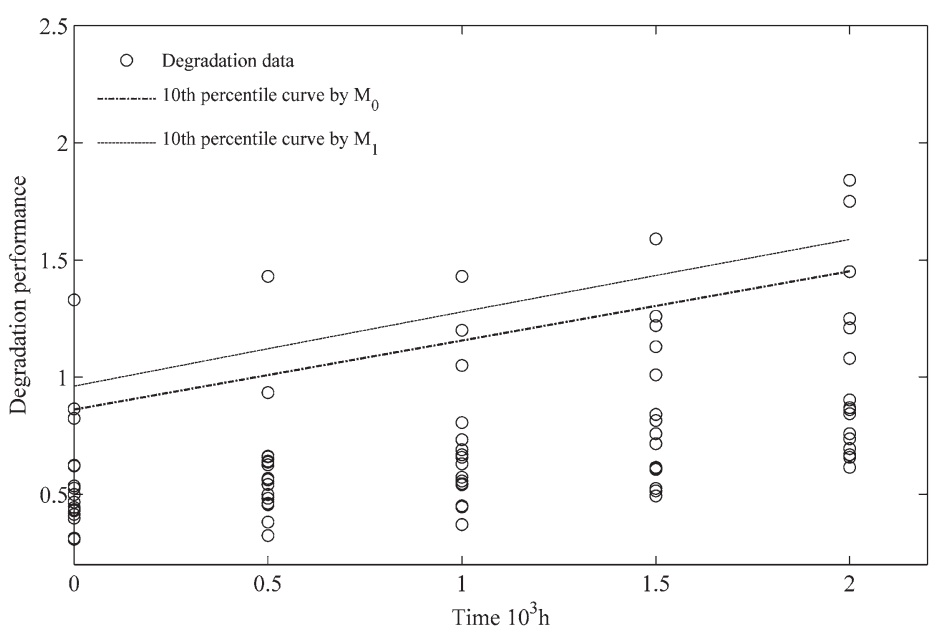

Fig. 4. Estimated 10th percentile curve of the two approaches

approximately linear over time. In such a case, the proposed model can effectively capture the degradation of storage disks without any transformation of test time and performance; viz. $x=t$ and $y=z$.

For comparison, let the time-transformed be $\Lambda(t)=a+b t$ in the reference model $\mathrm{M}_{1}$. We firstly apply $\mathrm{M}_{0}$ and $\mathrm{M}_{1}$ to fit the degradation data shown in Fig.1 to study the efficiency of the proposed model $\mathrm{M}_{0}$. Moreover, to show the necessity of incorporating measurement errors into the degradation model, the proposed model that removed the measurement error term is considered as model $\mathrm{M}_{2}$ and used to fit the degradation data. The Log-LF values and the AIC values are calculated to test the fit of each model. The obtained results are summarized in Table 6. From Table 6, it is clear that the proposed model gives a better fitting both in terms of the Log-LF and AIC.

To demonstrate the goodness of fit, the mean degradation paths estimated from the two approaches are compared with the sample average. Based on the estimates in Table 6, the estimated mean degradation paths are shown in Fig. 3, which shows that the estimated mean degradation path based on the proposed model is in conjunction with the sample average, and the two curves tally quite well. However, the estimated mean degradation path from the reference model $\mathrm{M}_{1}$ does not match the sample average well.

For further illustration, we calculate the 10th percentile of the block error rates of magneto-optic data storage disks. The estimated results are shown in Fig. 4. The 10th percentile of the block error rates $\hat{y}_{0.1}(t)$ means that $90 \%$ of the population of the disks performance degradation $y(t)$ should be below

Fig. 5. Residual plot for degradation data: (a) the proposed model $M_{0}$; (b) the reference model $M_{1}$ 
$\hat{y}_{0.1}(t)$. In the test span, 80 performance degradation data are measured. From Fig. 4, we observe that there are 8 above the 10th percentile of the block error rates $\hat{y}_{0.1}(t)$ estimated from the proposed model $\mathrm{M}_{0}$, while 6 performance degradation data above that from the reference model $\mathrm{M}_{1}$. Therefore, the proposed model gives more accurate results.

The median life and the 10th percentile of FTD, which play an important role in making maintenance plan, are estimated through the two approaches, as given in Table 7. As we know that, the estimated variance determines the interval between the median life $\hat{t}_{0.50}$ and the 10th percentile of FTD $\hat{t}_{0.10}$, and a larger variance estimation leads to a larger inter-

val. From Table 7, we can observe that the interval between the median life $\hat{t}_{0.50}$ and the 10th percentile of FTD $\hat{t}_{0.10}$ obtained from the reference model is smaller than that from the proposed method. This means a smaller variance estimation is obtained by the reference approach. As previously discussed, the mean degradation path of the proposed model better fits the sample average, and the 10th percentile of the block error rates of the proposed model is more reasonable. Consequently, if the results listed in Table 7 are used for maintenance schedule, the reference model will lead to premature maintenance which can reduce the product's utilization.

In addition, the residual plots are given based on the proposed model over time, the results are shown as Fig. 5. Fig. 5 indicates that the two models both perform well.

\subsection{Infrared light-emitting diodes degradation modeling}

Infrared light-emitting diodes (IRLEDs) are high-reliability optoelectronic devices widely used in communication systems. The performance of the devices is measured mainly by the variation ratio of

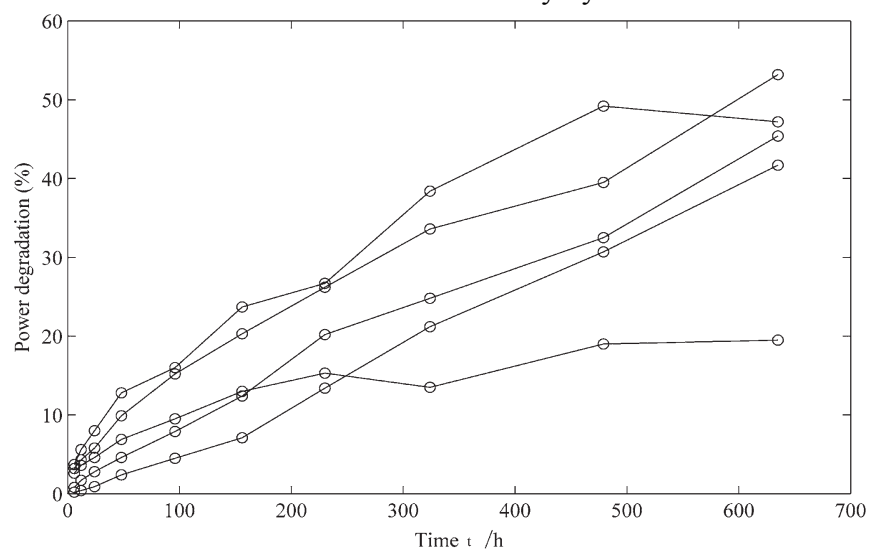

Fig. 6. The ratio of luminous power

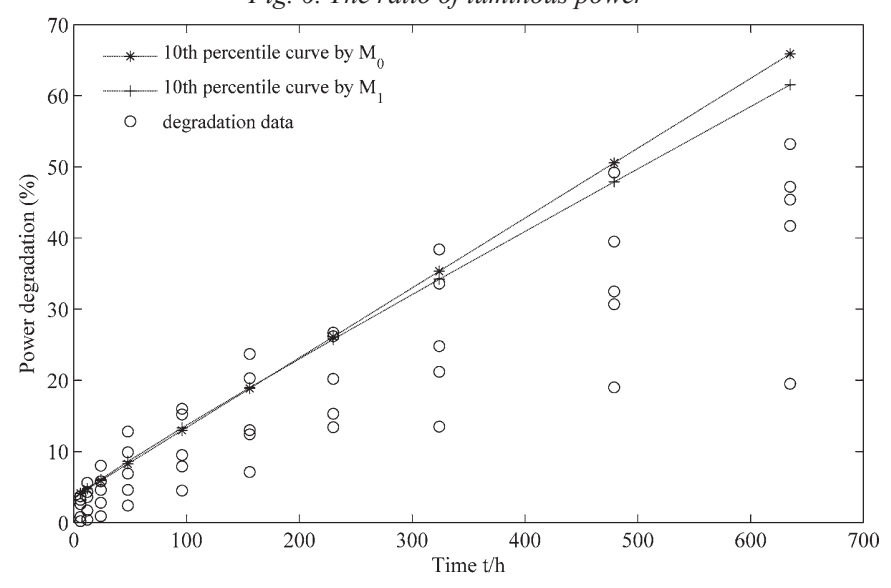

Fig. 7. Estimated 10th percentile performance curve of $M_{0}$ and $M_{1}$ able 8. Comparisons of two fitted degradation models

\begin{tabular}{|c|c|c|c|c|c|c|c|c|}
\hline Mode & & & & aramete & & & & \\
\hline \multirow[t]{2}{*}{$\mathrm{M}_{1}$} & $a$ & $b$ & $\mu$ & $\kappa^{2}$ & $\sigma^{2}$ & $\sigma_{e}^{2}$ & Log-LF & $\mathrm{AIC}$ \\
\hline & 1.7886 & 0.0909 & 0.8176 & 0.0082 & 1.1997 & 0.0078 & -110.69 & 233.38 \\
\hline \multirow[t]{2}{*}{$\mathrm{M}_{0}$} & $a$ & $b$ & $d_{1}$ & $d_{2}$ & -- & $\sigma_{e}^{2}$ & Log-LF & $\mathrm{AIC}$ \\
\hline & 1.6572 & 0.0760 & 1.4662 & 0.0173 & -- & 0.0075 & -110.69 & 231.38 \\
\hline $\mathrm{M}_{2}$ & 1.6169 & 0.0805 & 1.3107 & 0.0180 & -- & -- & -112.49 & 232.97 \\
\hline
\end{tabular}

Table 9. Comparisons of median life and 10th percentile of FTD

\begin{tabular}{ccc}
\hline \hline \multirow{2}{*}{ Failure time/h } & \multicolumn{2}{c}{ Model } \\
\cline { 2 - 3 } & $\mathrm{M}_{0}$ & $\mathrm{M}_{1}$ \\
\hline$\hat{t}_{0.50}$ & 228.05 & 235.86 \\
$\hat{t}_{0.10}$ & 157.50 & 156.31 \\
\hline \hline
\end{tabular}

luminous power. To estimate the reliability, 5 units were tested at the operating current of $320 \mathrm{~mA}$. A failure is said to have occurred if the ratio is greater than $19 \%$. The original data are presented in [19], as shown in Fig. 6.

According to a preliminary statistical analysis, we observe that it is not necessary to transform the time and performance. Again, $\mathrm{M}_{0}$, $M_{1}$ and $M_{2}$ are used to fit the data respectively. The ML estimates of the parameters and the maximum log-likelihood values are summarized in Table 8. From Table 8, it can be observed that although the maximum log-likelihood values are equal, the number of the unknown parameters of $\mathrm{M}_{0}$ is less than the other two models.

To test the goodness-of-fit, we calculate the median life $\hat{t}_{0.50}$ and the 10th percentile of the FTD $\hat{t}_{0.10}$ based on $\mathrm{M}_{0}$ and $\mathrm{M}_{1}$ respectively, and the results are given in Table 9. From the definition viewpoint, the 10th percentile of the FTD $\hat{t}_{0.10}$ means that an average of $90 \%$ of the population of products will not fail before $\hat{t}_{0.10}$. On the other hand, we know that the distance between $\hat{t}_{0.50}$ and $\hat{t}_{0.10}$ corresponds to the estimated dispersion. From Table 9, it is clear that the variance inferred from the proposed method $\mathrm{M}_{0}$ evolves slower than that from the reference method $\mathrm{M}_{1}$.

Furthermore, the 10th percentiles of the ratio of luminous power of 5 IRLEDs are given by the proposed model and the reference model respectively. The results are depicted in Fig. 7. As can be seen from this figure, the ratio of the number of test data above the 10th percentile and the total number of test data obtained by the proposed model is more close to $10 \%$. Meanwhile, the residual plots shown in Fig. 8 also demonstrate that the proposed model can perform well.

The reliability is estimated based on the proposed model. Meanwhile, we extrapolate the degradation paths to the failure threshold to obtain the pseudo failure time for each unit and calculate the empirical reliability by Kaplan-Meier method. The results are displayed in Fig. 9. Fig. 9 shows that the estimated reliability curve performs well with the empirical reliability.

Moreover, from the viewpoint of sample size, there are 5 units in IRLEDs degradation test. And 5 can be considered as a small sample. So it can be concluded that the proposed approach can ensure a good performance no matter the sample size is large enough or considerably small. 

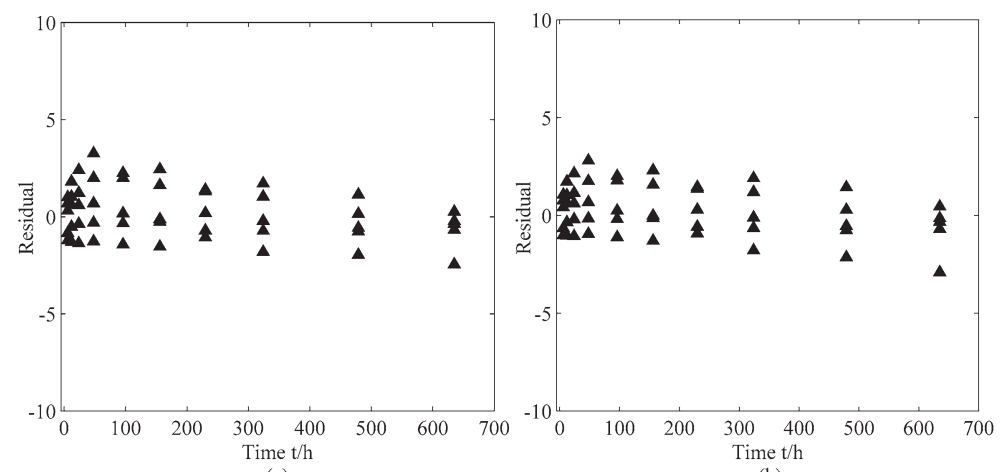

Fig. 8. Residual plot for degradation data: (a) the proposed model $M_{0}$; (b) the reference model $M_{1}$

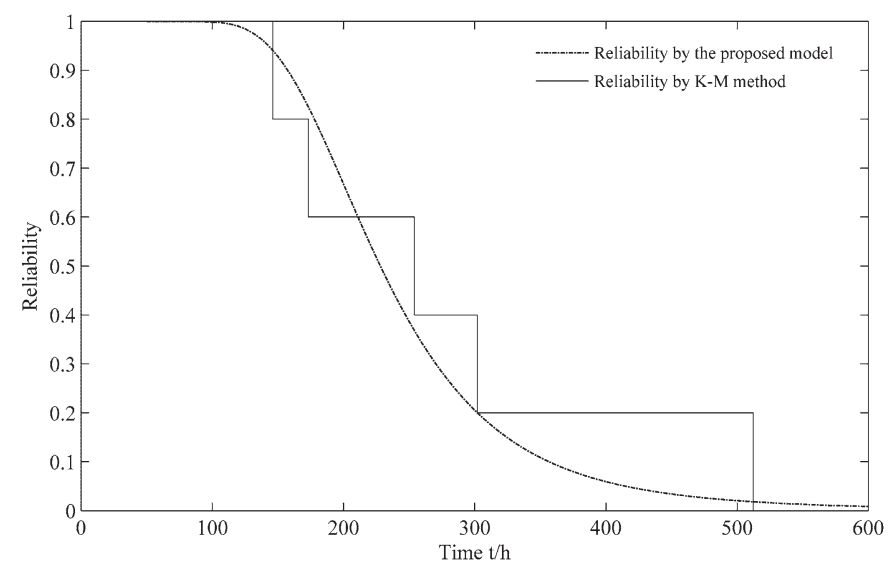

Fig. 9. Reliability function

\section{Conclusion}

In this paper, we propose a Wiener process model with linear mean function and standard deviation function, which allows us to take measurement error into considerations simultaneously. Comparing with the traditional time-transformed Wiener process, the proposed model can be considered as a more generalized Wiener process model with two different transformed time scales. Statistical inferences of this model are discussed, and a close form of product's median life and percentile of the FTD are also derived.

Simulation studies show that analysis precision can be enhanced while involving more items or setting more inspection times, and reasonable median life and FTD percentiles can still be derived with a considerably small sample size of $m=5$ via the proposed method. Empirical studies with storage disks and IRLEDs degradation illustrate the reasonability and effectiveness of the proposed approach.

\section{Acknowledgement}

The authors are grateful to the anonymous reviewers, and the editor, for their critical and constructive review of the manuscript. This study was co-supported by the National Natural Science Foundation of China (Grant No. 11202011 and 61203093), National Basic Research Program of China (973 Program) (Grant No. 2012CB720000), and Fundamental Research Funds for the Central Universities (Grant No. YWK13HK11).

\section{References}

1. Beasley J E, Chu P C. A genetic algorithm for the set covering problem. European Journal of Operational Research 1996; 94: 392-404, http:// dx.doi.org/10.1016/0377-2217(95)00159-X.

2. Chaluvadi V N H. Accelerated life testing of electronic revenue meters. In: Clemson University, 2008.

3. Crowder M, Lawless J. On a scheme for predictive maintenance. European Journal of Operational Research 2007; 176: 1713-1722, http:// dx.doi.org/10.1016/j.ejor.2005.10.051.

4. Hamada M S, Wilson A, Reese C S, Martz H. Bayesian reliability: Springer Science \& Business Media: 2008, http://dx.doi.org/10.1007/9780-387-77950-8

5. Lawrence D. Handbook of genetic algorithms. Van No strand Reinhold, New York 1991.

6. Lu C J, Meeker W Q. Using Degradation Measures to Estimate a Time-to-Failure Distribution. Technometrics 1993: 161-174, http://dx.doi. org/10.1080/00401706.1993.10485038.

7. Meeker W Q, Escobar L A. Statistical methods for reliability data: John Wiley \& Sons: 2014.

8. Meeker W Q, Hamada M. Statistical tools for the rapid development and evaluation of high-reliability products. Reliability, IEEE Transactions on 1995; 44: 187-198, http://dx.doi.org/10.1109/24.387370.

9. $\quad$ Nair V N. [Estimation of Reliability in Field-Performance Studies]: Discussion. Technometrics 1988; 379-383.

10. Park C, Padgett W J. New cumulative damage models for failure using stochastic processes as initial damage. Reliability, IEEE Transactions on 2005 ; 54: 530-540.

11. Peng C, Tseng S. Mis-specification analysis of linear degradation models. Reliability, IEEE Transactions on 2009; 58: 444-455.

12. Pham H T, Yang B, Nguyen T T. Machine performance degradation assessment and remaining useful life prediction using proportional hazard model and support vector machine. Mechanical Systems and Signal Processing 2012; 32: 320-330, http://dx.doi.org/10.1016/j. ymssp.2012.02.015.

13. Tseng S T, Tang J, Ku I H. Determination of burn-in parameters and residual life for highly reliable products. Naval Research Logistics (NRL) 2003; 50: 1-14, http://dx.doi.org/10.1002/nav.10042.

14. Tseng S, Peng C. Stochastic diffusion modeling of degradation data. Journal of Data Science 2007; 5: 315-333.

15. Wang W, Dragomir-Daescu D. Reliability quantification of induction motors-accelerated degradation testing approach. In: Reliability and Maintainability Symposium, 2002. Proceedings. Annual: IEEE 2002: 325-331.

16. Wang X. Wiener processes with random effects for degradation data. Journal of Multivariate Analysis 2010; 101: 340-351, http://dx.doi. org/10.1016/j.jmva.2008.12.007.

17. Wang Z, Fu H, Zhang Y. Analyzing Degradation by an Independent Increment Process. Quality and Reliability Engineering International 2014; 30: 1275-1283, http://dx.doi.org/10.1002/qre.1547. 
18. Whitmore G A, Schenkelberg F. Modelling accelerated degradation data using Wiener diffusion with a time scale transformation. Lifetime Data Analysis 1997; 3: 27-45, http://dx.doi.org/10.1023/A:1009664101413.

19. Yang G. Life cycle reliability engineering: John Wiley \& Sons 2007, http://dx.doi.org/10.1002/9780470117880.

20. Ye Z, Wang Y, Tsui K, Pecht M. Degradation data analysis using Wiener processes with measurement errors. Reliability, IEEE Transactions on 2013; 62: 772-780.

21. Zuo M J, Jiang R, Yam R. Approaches for reliability modeling of continuous-state devices. Reliability, IEEE Transactions on 1999; 48: 9-18, http://dx.doi.org/10.1109/24.765922.

\section{Zhihua WANG \\ Junxing LI \\ Yongbo ZHANG \\ Huimin FU}

School of Aeronautic Science and Engineering

Beihang University

XueYuan Road No.37

HaiDian District

Beijing 100083, China

\section{Chengrui LIU}

Science and Technology on Space Intelligent Control

Laboratory

Beijing Institute of Control Engineering

No.16 3th South Zhongguancun Street

Haidian District

Beijing 100191, China

\section{Sridhar KRISHNASWAMY}

Department of Mechanical Engineering

Northwestern University

633 Clark Street, Evanston

IL 60208

Evanston, USA

E-mail: wangzhihua@buaa.edu.cn, lijun-xing2008@163.com, zhangyongbo@buaa.edu.cn, fuhuimin@263.net, liuchengrui@buaa.edu.cn, s-krishnaswamy@northwestern.edu 